\title{
TIC e Educação em Química: análise das publicações nos anais do Encontro Nacional de Ensino de Química entre 2008 a 2018
}

\author{
ICT and Education in Chemistry: analysis of publications in the annals of the \\ National Meeting of Teaching of Chemistry between 2008 to 2018 \\ Geovane de Melo Leal \\ Davi da Silva \\ Dihêgo Henrique Lima Damacena \\ Herbert Gonzaga Sousa
}

\begin{abstract}
Resumo: O presente trabalho apresenta uma análise dos trabalhos publicados na linha temática Tecnologia da Informação e Comunicação no Ensino (TIC) nos anais do Encontro Nacional de Ensino de Química (ENEQ), entre 2008 a 2018. Esta pesquisa é de caráter bibliográfico e tem como objetivo apresentar um levantamento dos trabalhos publicados na temática TIC nas últimas seis edições do ENEQ, visando mapear e analisar como a temática vem sendo debatida na área de educação/ensino de Química. Observou-se que, ao longo das edições, houve um aumento expressivo de pesquisadores que sinalizam para novas discussões e debates no meio acadêmico e científico acerca da temática TIC como possibilidade de educação/ensino de Química no decorrer dos encontros. Além disso, foram apresentados, ainda, os níveis de ensino em que eram abordadas as pesquisas. Foi possível identificar que a temática TIC está cada vez mais presente nas salas de aulas e alcança diferentes níveis de escolaridade, do Ensino Fundamental aos cursos de ensino superior.
\end{abstract}

Palavras-chave: Ensino de Química; ENEQ; Tecnologias na Educação.

Abstract: The present study shows an analysis of the works published in the thematic line Information and Communication Technology in Education (ICT) in the annals of the National Meeting Chemistry Teaching (ENEQ), between 2008 and 2018. This research is bibliographic character and aims to present a survey of the works published in the ICT theme in the last six editions of ENEQ, aiming to map and analyze how the theme has been debated in the area of Chemistry education/teaching. It was observed that, throughout the editions, there was a significant increase of researchers that indicate for further discussions and debates in the academic and scientific environment on the ICT theme as an educational possibility of chemistry education/teaching during the meetings. In addition, the levels of education at which the research was approached were also presented. It was possible to identify that the ICT theme is increasingly present in classrooms and reaches different levels of education, from elementary school to higher education courses.

Keywords: Chemistry teaching; ENEQ; Technologies in Education.

\section{Introdução}

A educação em Química é um tema que vem sendo amplamente discutido por pesquisadores e estudiosos da área de ensino. Essa discussão tem por finalidade buscar por estratégias e metodologias que visem à melhoria 
do processo de ensino e de aprendizagem da disciplina de Química nos diversos níveis educacionais. Nesse sentido, percebe-se que, ao longo dos últimos anos, houve uma crescente produção de pesquisas e estudos que permeiam a abordagem tecnologias da informação e comunicação (TIC) no ensino de Química em periódicos e em diversos eventos nacionais de divulgação cientifica.

Particularmente, as tecnologias, na prática docente, atuam como instrumento de aquisição de informação e conhecimento e estão ainda mais integradas na educação. Para Tavares, Souza e Correia (2013), em meio aos vários recursos tecnológicos com potencial didáticos disponíveis para a mediação escolar, a educação se encontra mais ainda interligada com as tecnologias. Estes recursos se caracterizam como uma forma de inovação da prática pedagógica a partir de novas abordagens sobre educação/ensino de Química por intermédio de ferramentas tecnológicas que favorecem para a construção de conhecimentos de maneira interativa e significativa, ao mesmo tempo em que promovem uma autonomia e uma dinâmica na aprendizagem dos alunos.

A presença das tecnologias no contexto educativo possibilita novos recursos informacionais, comunicativos e novas maneiras de se aprender. Sendo assim, a disseminação de informações de cunho educacional de modo descentralizado por meio das mídias digitais colabora para que os estudantes se tornem os principais responsáveis no seu aprendizado e na construção de seus conhecimentos. E o professor torna-se um intermediador de conhecimento e orientador na prática educativa no ensino de Química.

Assim, os dispositivos tecnológicos constituem uma importante ferramenta educativa metodológica que auxiliam no processo de formação do aluno na busca de conhecimento, ou seja, com o uso das mídias tecnológicas, ampliam-se as possibilidades interativas de trocas de conhecimentos entre alunos e professores de forma dinâmica e eficaz na prática educativa.

Neste sentido, fica claro que é fundamental conhecer as pesquisas apresentadas na linha temática TIC nos anais do Encontro Nacional de Ensino de Química (ENEQ), tendo em vista que o evento vem se consolidando como 
um ambiente muito importante para a socialização e divulgação de estudos e pesquisas que norteiam o desenvolvimento de práticas docentes mediadas por recursos tecnológicos na educação/ensino de Química.

Diante disso, esta pesquisa se justifica pela necessidade de analisar e levantar as diferentes abordagens de ensino mediadas pelas tecnologias como possibilidade na educação/ensino de Química. É importante salientar que se faz necessário conhecer como vem sendo discutido, no cenário nacional, a educação/ensino de Química frente às novas tecnologias em uma sociedade cada vez mais atualizada no sentido tecnológico.

Desse modo, o presente estudo tem como objeto as tecnologias da informação e comunicação no contexto da educação/ensino de Química, com o intuito de responder ao seguinte questionamento: como a temática TIC vem sendo debatida por pesquisadores, professores e acadêmicos da área nos anais do Encontro Nacional de Ensino de Química, entre o período de 2008 a 2018, diante das diversas possibilidades na educação/ensino em Química?

A partir desta perspectiva, a pesquisa tem como objetivo apresentar um levantamento dos trabalhos apresentados na linha temática TIC nos anais do Encontro Nacional de Ensino de Química nas últimas seis edições (2008 a 2018), visando mapear e analisar como a temática vem sendo debatida na área da educação/ensino de Química. Especificamente, visa Identificar e analisar os anais do ENEQ entre as edições citadas e refletir sobre a importância das TICs na educação/ensino de Química.

A escolha pelos anais do ENEQ como fonte de consulta para a pesquisa se justifica por este ser o maior e principal evento em nível nacional na área de educação/ensino de Química, é realizado periodicamente a cada dois anos e vem possibilitando uma troca de experiências muito importante entre os profissionais da área de diversas regiões do país na busca por melhorias no ensino de Química.

\section{Fundamentação teórica}

No âmbito tecnológico, o qual a sociedade se encontra inserida, as tecnologias digitais de informação constituem-se como um novo dispositivo de 
compartilhamento e disseminação de informações por meio de recursos e objetos digitais disponíveis nas redes da internet e das telecomunicações. Salla, Caixeta e Silva (2015, p. 90) afirmam que "a chave para a mediação é a comunicação. No ambiente digital, a comunicação pode acontecer pelo compartilhamento de mensagens de texto e de voz, vídeos ou imagens".

Com os avanços das ciências e das tecnologias notam-se as diversas contribuições destes recursos para a sociedade contemporânea, uma vez que se ampliou o acesso à informação e comunicação por meio da diversidade de dispositivos de mídias digitais. "A inserção tecnológica na esfera social se configura como um fator essencial para a difusão, familiarização e utilização das TIC nos diferentes campos sociais" (SILVA; SOARES, 2018, p. 640).

No contexto educacional, as tecnologias se caracterizam como uma importante ferramenta pedagógica de multiplicação de saberes que contribuem para consolidar e ampliar os novos ambientes de aquisição e disseminação do conhecimento. Machado (2016) afirma que ao inserir as mídias tecnológicas na educação potencializa-se a prática docente através de recursos didáticos interativos que favorecem para uma aprendizagem mais significativa dos conteúdos.

Partindo dessa concepção, o desenvolvimento de uma educação/ ensino de Química mediado pelas tecnologias educativas contribui para uma visão mais ampla do conhecimento através das potencialidades didáticas de ensino que permitam a construção de uma aprendizagem ativa e colaborativa. De acordo com Leite e Leão (2015, p. 294):

Estas ferramentas estimulam a experimentação, reflexão e a geração de conhecimentos individuais e coletivos, favorecendo a conformação de um ciberespaço de interatividade que contribui a criar um ambiente de aprendizagem colaborativo.

Com base nos autores acima, as tecnologias compõem um conjunto de recursos e mídias digitais que contribuem para a implementação de novas abordagens e perspectivas nos processos de ensino e aprendizagem. Segundo Flores (2014), as tecnologias da informação e comunicação colaboram para uma maior democratização do acesso ao conhecimento de forma mais ampla e abrangente, contribuindo assim, para uma educação mais construtiva. 
Nesse contexto, fica claro que as tecnologias na educação/ensino de Química enquadram-se como uma estratégia que permite uma articulação de conhecimentos tecnológicos e científicos em um contexto social que podem favorecer para produção de novos significados na aprendizagem, assim como, fornecer varias possibilidades de saberes na prática docente. Nas palavras de Lima e Moita (2011, p. 135), "a adoção de recursos tecnológicos na prática educativa da disciplina de química requer planejamento, cuja metodologia esteja centrada na realidade da vida e no social".

Diante dessa perspectiva, o educador apresenta uma característica de mediador do processo pedagógico amparada em uma nova abordagem que incorpore as mídias tecnológicas baseadas no contexto social dos alunos. Diante desta realidade, as TICs propõem aspectos que englobam 0 desenvolvimento de uma alfabetização tecnológica nas atividades práticas pedagógicas de aula, de forma que favorecem para uma participação ativa do aluno no processo educacional. (LUCENA; SANTOS; SILVA, 2013).

É notável que o emprego das mídias tecnológicas no âmbito escolar tem sua importância destacada no processo de ensino e aprendizagem, pois contribuem para promoção de uma dinâmica na educação/ensino de Química mais interativa entre o educador e o educando. As tecnologias envolvidas no processo educativo contribuem para um novo espaço de diálogo e troca de conhecimentos por meio de recursos que favorecem para uma aprendizagem mais significativa (MARTINS; SERRÃO; SILVA, 2020).

Cabe ressaltar que as tecnologias têm possibilitado mudanças expressivas na prática docente com a inserção dos recursos didáticos digitais, tornando mais evidente e clara a necessidade de atualizar as práticas educacionais e, portanto, os modelos pedagógicos de ensino (LEITE, 2015). Com a mediação do ensino proporcionada pelos recursos multimídias, abremse novos horizontes de conhecimento e amplia-se a capacidade de aprendizagem.

Logicamente, o educador deve estar preparado para utilizar as diversas mídias tecnológicas como uma estratégia para aprimorar suas práticas de ensino para além do contexto de sala de aula, uma vez que a evolução 
tecnológica vem ampliando o potencial da educação com os novos métodos de se comunicar, informar e aprender. "As TICs colocaram em relevo novas formas de acesso à informação, bem como de novas formas de interação e comunicação, mediadas no ciberespaço". (PAULETTI; CATELLI, 2013, p. 387).

Nessa perspectiva, entende-se que é fundamental que o docente tenha conhecimento para fazer uso das tecnologias na sala de aula. Logo, se evidencia que é preciso que estes novos recursos sejam explorados durante a formação inicial do professor, a fim de possibilitar o desenvolvimento de habilidades e competências para inserir e utilizar as ferramentas tecnológicas na sua prática educativa (JUNIOR; CIRINO, 2016).

Para Fernandes et al. (2019), a Internet vem diminuindo distâncias e abrindo novos espaços na educação através de programas a distância que incorporam tecnologia educacional à Informática e às redes telecomunicativas, permitindo rapidez e agilidade na comunicação. Em geral, o progresso das novas tecnologias destaca-se como uma aliada na educação, em meio à produção e difusão de conhecimento proporcionada por seus recursos midiáticos que ampliam as formas de se ensinar e de se aprender Química.

Nesse contexto, as tecnologias digitais são apontadas como um mecanismo de transformação das práticas docentes, colaborando para o desenvolvimento de capacidades que visam novas formas de aprender em meio ao contexto dos múltiplos recursos contemporâneos (OLIVEIRA; NASCIMENTO; BOTTENTUIT JUNIOR, 2018).

\section{Metodologia}

A pesquisa pode ser entendida como um conjunto de procedimentos formais que tem por finalidade buscar soluções e respostas para determinados fatos e problemas, a partir de um método científico. Pesquisar se constitui na prática um caminho para se descobrir novos conhecimentos (SOUZA; SANTOS; DIAS, 2013).

Desta forma, a referida pesquisa foi realizada com uma abordagem qualitativa do tipo exploratória descritiva de caráter bibliográfico, fundamentado em Fonseca (2012, p.21) "a pesquisa bibliográfica dever ser somada, 
necessariamente, a todo e qualquer tipo de pesquisa ou trabalho cientifico, constituindo uma base teórica para o desenvolvimento de todo trabalho de investigação em ciência".

Partindo desse contexto, a apreciação dos trabalhos versou inicialmente na delimitação do corpus da pesquisa a ser investigado. Após a definição do corpus da pesquisa para a realização do estudo, foram apreciados os resumos e trabalhos completos publicados na linha temática TIC nas edições do ENEQ entre o período de 2008 a 2018. Os trabalhos selecionados foram classificados de acordo com as proposições teóricas acerca da Análise de Conteúdos de Bardin (2011). Esta análise permite compreender a pesquisa em sua totalidade, com a finalidade de promover novas reinterpretações mais detalhadas desde a discussão dos dados coletados.

O corpus de análise da pesquisa foram os anais do ENEQ nas edições de 2008 a 2018. Foram conferidos 258 trabalhos publicados na linha temática TIC. Os trabalhos apreciados foram quantificados por meio de um número de ordem, sendo que o primeiro trabalho, de número 1 , foi apresentado no encontro de 2008 e o último trabalho, de número 258 , apresentado no encontro de 2018. Enfatiza-se que os trabalhos quantificados corresponderam à ordem disponibilizada pelos anais do evento na linha temática investigada, que se encontram sobre domínio público. Logo após a leitura dos resumos e trabalhos completos para a triagem dos dados e realização da análise, seguiu-se para a fase de classificação dos trabalhos para uma posterior intepretação dos dados.

\section{Resultados e Discussão}

Após a realização da análise do material dos anais do ENEQ referente às últimas 6 (seis) edições do evento, primeiramente, foi levantado 0 quantitativo dos trabalhos apresentados no período entre 2008 a 2018, e constatou-se que, dos 5.323 trabalhos, apenas 258 foram apresentados na linha temática TIC, correspondendo a $4,82 \%$ dos trabalhos apresentados nestas edições. Ainda com base nos dados da tabela 1, é possível verificar um crescente aumento no número total de trabalhos publicados nos anais do ENEQ em cada edição nos últimos 10 (dez) anos, evidenciando, assim, que o 
evento vem alcançando cada vez mais pessoas em cada edição. Contudo, na edição do ENEQ do ano de 2018 houve uma queda, um tanto significativa, no número geral de trabalhos no evento e no número de trabalhos aprovados na temática TIC. Nesse sentido, percebe-se que essa queda pode ter relação com a dificuldade de se conseguir financiamento para a divulgação da Ciência, que, ao longo dos anos, vem se agravando cada vez mais.

Tabela 1 - Número de trabalhos do ENEQ entre 2008 a 2018

\begin{tabular}{cccccc}
\hline Edição & Ano & $\begin{array}{c}\text { Local do } \\
\text { Evento }\end{array}$ & $\begin{array}{c}\text { Número de } \\
\text { Trabalhos }\end{array}$ & $\begin{array}{c}\text { Trabalhos na } \\
\text { Linha Temática } \\
\text { TIC }\end{array}$ & $\begin{array}{c}\text { Percentual } \\
\text { por } \\
\text { Edição }\end{array}$ \\
\hline XIV & 2008 & UFPR/PR & 462 & 38 & $8,22 \%$ \\
XV & 2010 & UNB/DF & 573 & 33 & $5,75 \%$ \\
\hline XVI & 2012 & UFBA/BA & 930 & 41 & $4,40 \%$ \\
\hline XVII & 2014 & UFOP/MG & 1400 & 52 & $3,64 \%$ \\
\hline XVIII & 2016 & UFSC/SC & 1602 & 74 & $4,61 \%$ \\
\hline XIX & 2018 & UFAC/AC & 356 & 20 & $5,61 \%$ \\
\hline
\end{tabular}

Fonte: Elaborado pelos autores.

Percebe-se, a partir dos dados quantitativos, que no período estabelecido entre 2008 a 2018, foram publicados nos anais do ENEQ 258 trabalhos na linha temática TIC, sendo que 151 correspondem aos trabalhos apresentados como resumos e 107 como trabalhos completos. A figura 1 apresenta a produção dos trabalhos de forma mais detalhada na linha temática investigada nas edições selecionadas. 
Figura 1 - Quantitativo de trabalhos na linha temática TIC por ano do ENEQ

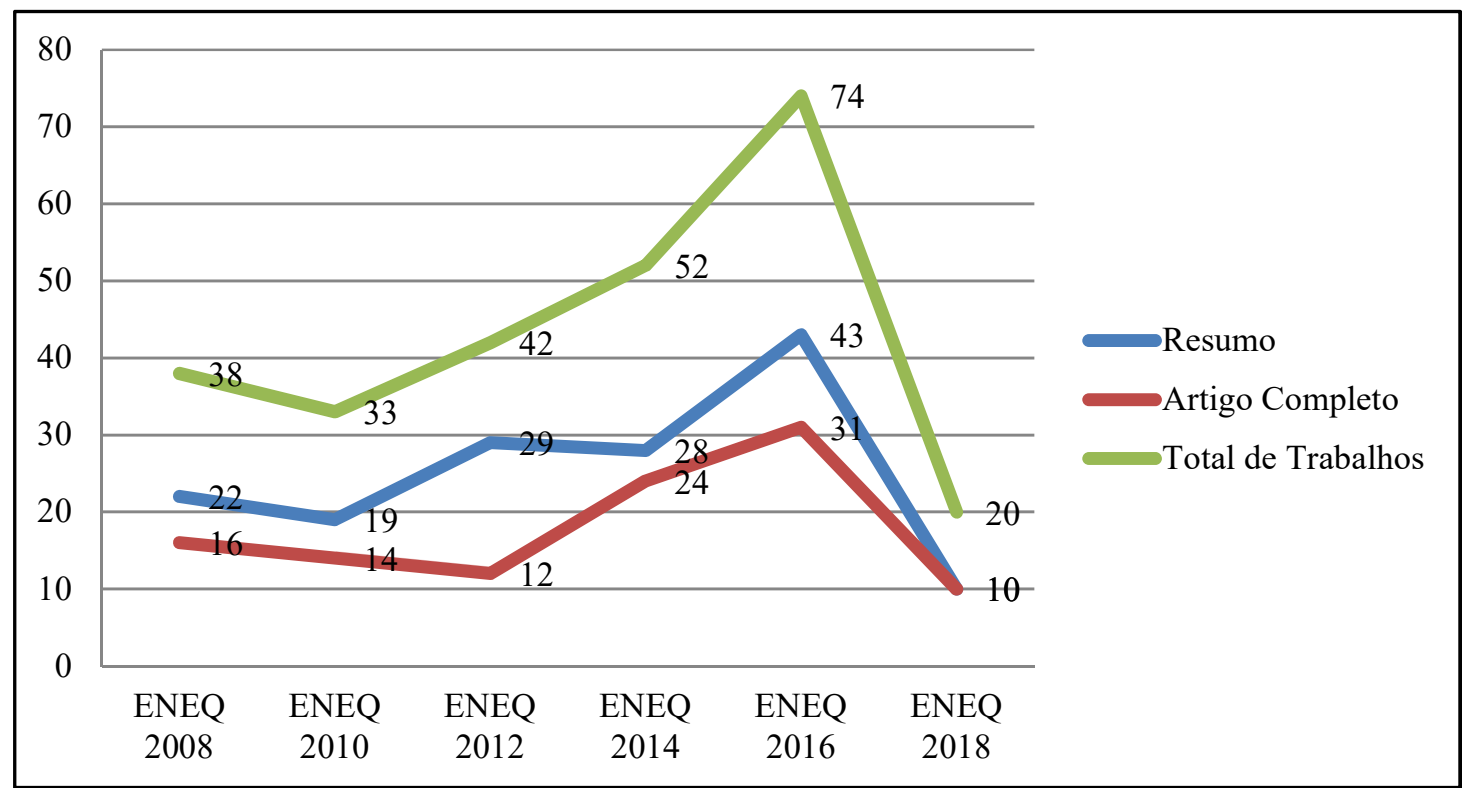

Fonte: Elaborado pelos autores.

Pode-se observar na figura 1 que fica evidente um aumento gradativo da produção de trabalhos direcionados para a linha temática TIC, entre as edições do ano de 2012 a 2016, em que, nesse intervalo de tempo, obteve-se um crescimento de 38 para 74 trabalhos publicados nos anais, evidenciando que, em meio ao crescimento tecnológico mundial, a comunidade acadêmica e pesquisadores estudam novas formas de inserir, inovar e potencializar o ensino de Química com estes recursos tecnológicos na educação.

Em relação aos tipos de trabalhos no ENEQ, verifica-se que nas edições de 2008 a 2016 o número de trabalhos publicados como resumo simples é superior ao número de trabalhos completos. Entretanto, na edição do evento em 2018 os números de resumos e trabalhos completos apresentaram a mesma quantidade de trabalhos publicados.

Apesar da não linearidade de crescimento das produções publicadas nos anais do ENEQ sobre a temática investigada, é notável que, ao longo das edições, houve um aumento expressivo de pesquisadores que sinalizam para novas discussões e debates no meio acadêmico e científico acerca das Tecnologias de Informação e Comunicação como possibilidade educacional na educação/ensino de Química no decorrer dos anos. 
$\mathrm{Na}$ Tabela 2, são apresentados os trabalhos conforme $\circ$ tipo de Modalidade Acadêmica, das quais os dados analisaram o grau de formação acadêmica ou atuação profissional do autor principal de cada trabalho (PQpesquisador, FM- professor de ensino fundamental e médio, PG- acadêmico de pós-graduação, IC- graduando, TC- professor de ensino técnico). O que revelou dados importantes sobre as pesquisas na linha de abordagem TIC acerca de como vem sendo debatida e consolidada pelos profissionais da química, com ênfase na educação básica.

Tabela 2 - Relação de trabalhos por Modalidade Acadêmica.

\begin{tabular}{ccccccc}
$\begin{array}{c}\text { MODALIDADE } \\
\text { ACADÊMICA }\end{array}$ & $\mathbf{2 0 0 8}$ & $\mathbf{2 0 1 0}$ & $\mathbf{2 0 1 2}$ & $\mathbf{2 0 1 4}$ & $\mathbf{2 0 1 6}$ & $\mathbf{2 0 1 8}$ \\
\hline PQ & 4 & 4 & 5 & 7 & 12 & 5 \\
FM & 1 & 8 & 3 & 6 & 10 & 1 \\
PG & 20 & 13 & 8 & 14 & 20 & 7 \\
IC & 13 & 8 & 24 & 25 & 31 & 6 \\
TC & - & - & 1 & - & 1 & 1 \\
\hline
\end{tabular}

Fonte: Elaborado pelos autores.

Com base na apreciação dos dados, fica evidente que a participação dos acadêmicos de graduação e de pós-graduação é bem significativa no período analisado. Como demonstra a Tabela 2, essa tendência crescente pode estar associada à ampliação de grupos de pesquisas que tenham como área de interesse a educação/ensino de Química na abordagem TIC na formação inicial por meio do Programa Institucional de Bolsas de Iniciação à Docência (PIBID) nos cursos de licenciatura, e na produção bibliográfica dos programas de pós-graduação em nível de Mestrado e Doutorado nas universidades. Os dados apresentados dialogam diretamente com o estudo de Nogueira (2016), aos quais os dados apontados, mostraram que, no encontro de 2010 , do total geral dos trabalhos, 7,6\% eram relacionados ao PIBID, em 2012 verificou-se que $12,8 \%$ dos trabalhos abordavam o programa, e o evento de 2014 , apontou que $14,5 \%$ dos trabalhos eram direcionados às discussões sobre o PIBID. 
É possível citar, ainda, diversas pesquisas que corroboram com a premissa da escrita na formação inicial do professor, dentre eles o de Matsumoto et al. (2008), Cabral e Castro (2018), Wenzel et al. (2019). Estas produções apresentam algumas das contribuições da escrita na pesquisa científica na formação inicial do professor, buscando enfatizar uma reflexão dos futuros professores acerca da pratica docente a fim de possibilitar o desenvolvimento de recursos e novas metodologias no ensino a partir de pesquisa focadas na educação/ensino de Química.

Por meio da análise, nota-se que os encontros do ano de 2010 e 2016 se sobressaem por apresentar um número considerável de participação dos profissionais da educação básica, enfatizando a contribuição do diálogo entre as universidades e as escolas de educação básica, a fim de corroborar com pesquisas na área de ensino e nas práticas pedagógicas de sala de aula.

Os dados também mostraram que a participação de pesquisadores na linha temática TIC, apresenta-se, em primeiro momento, em um número bem modesto nas edições. Entretanto, cabe ressaltar que na apreciação dos dados de cada trabalho, foram conferidos os nomes do primeiro autor na análise. Cabe destacar, ainda, que a maior parte dos trabalhos contém coautores e isto evidência uma forte participação destes nos encontros analisados. Além disso,, destaca-se que a temática TIC apresenta discussões por autores de diversas modalidades acadêmicas, o que enfatiza um aumento das produções cientificas acerca deste campo de estudo, de modo a contribuir para difusão das diferentes abordagens da temática TIC no meio acadêmico educacional.

Considerando a distribuição geográfica das regiões e a instituição de pesquisa identificada nos trabalhos ao quais os autores estão vinculados, foi possível descrever de modo quantitativo o número de publicações catalogadas acerca da temática pesquisada com base em cada região. A figura 2 apresenta o número de trabalhos acerca da classificação regional identificada nos trabalhos. 
Figura 2 - Trabalhos por região na temática TIC nas edições ENEQ de 2008 a

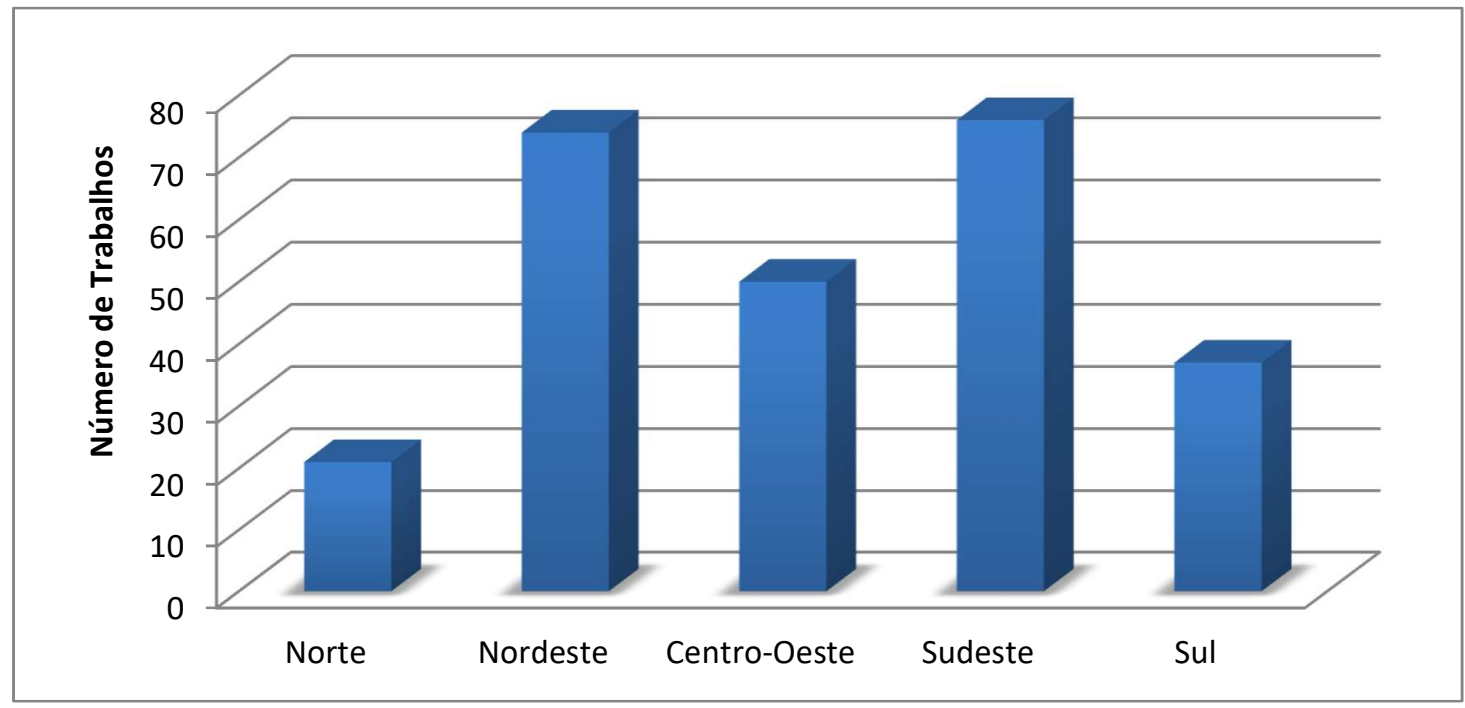

Fonte: Dados da Pesquisa.

Pela análise da figura 2 é possível demonstrar que a produção dos trabalhos publicados nos anais do ENEQ, no recorte temporal desta investigação, contemplam diversas regiões brasileiras, como é apresentado no mapeamento do número de publicações catalogadas por região (Norte, Nordeste, Centro-Oeste, Sudeste e Sul). Além disso, baseado da análise dos dados, verificou-se que a região brasileira que apresenta o maior número de publicações na linha temática TIC foi, de acordo com a pesquisa, a região Sudeste, com um total de 76 trabalhos publicados no período compreendido. Posteriormente, a região Nordeste, que apresentou 74 publicações. Seguindo, a região Centro-Oeste, com 51 trabalhos publicados, ainda, a região Sul, com 36 publicações e, por fim, a região Norte, com 21 publicações no período respectivo.

Segundo a decisão da comunidade de pesquisadores sobre a realização do ENEQ, a partir de 2016, ficou decidido haver necessidade de que o evento fosse realizado em todas as regiões geográficas do País. Desse modo, essa decisão contribui para uma maior descentralização dos encontros, uma vez que essa ação promove uma expansão e distribuição do número de pesquisadores 
sobre a educação/ensino de Química em todo o território Brasileiro (SOARES; MESQUITA; REZENDE, 2017).

Nesse contexto, fica claro, pela observação dos dados apresentados, que os pesquisadores das diversas regiões do Brasil vêm demonstrando interesse pelo estudo da temática TIC na educação/ensino de Química por meio de pesquisas que visam a renovação de estratégias para o ensino desta ciência. Lucena, Santos e Silva (2013) afirmam que essas tecnologias proporcionam novas abordagens que podem contribuir para um crescimento significativo no processo de ensino e aprendizagem.

Acerca dos dados elencados anteriormente, como o número de publicações e região dos autores da pesquisa, buscou-se também averiguar os níveis de ensino de acordo com as seguintes categorias: fundamental, médio, técnico, educação de jovens e adultos (EJA), superior e geral, sendo abordados nas publicações por cada autor. A categoria geral apresenta trabalhos que não possuem um nível de ensino específico e trabalhos que são direcionados aos profissionais de Química. O resultado é apresentado conforme os níveis de ensino na figura 3.

Figura 3 - Níveis de Ensino abordados nos trabalhos dos anais do ENEQ

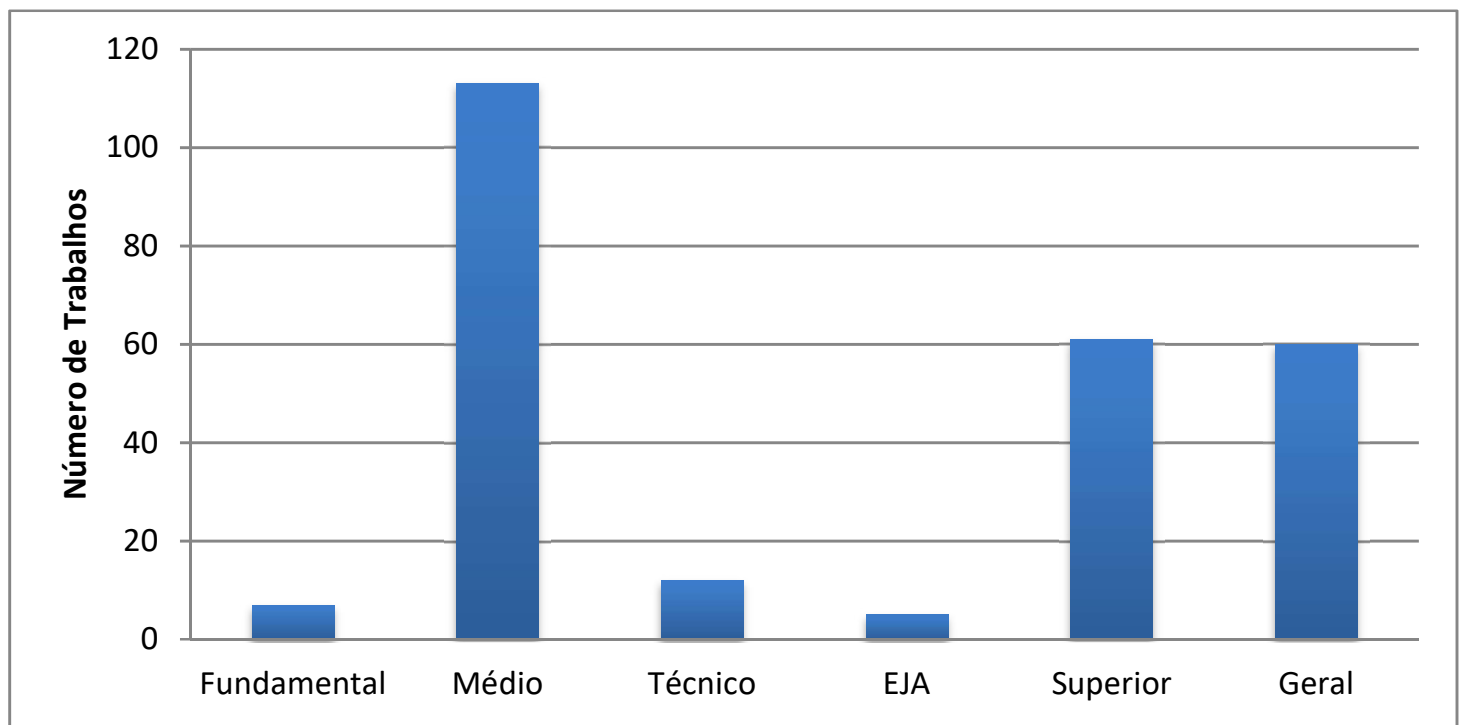

Fonte: Dados da Pesquisa

Com base na análise da figura 3 , evidencia-se que a maior parte dos trabalhos publicados compreende, como foco da pesquisa, o Ensino Médio com abordagem e discussões na disciplina de Química, tendo como principal 
objeto de estudos propostas de mediação no ensino por meio de recursos tecnológicos. Entretanto, ainda foram considerados diferentes níveis de ensino, com ênfase no Ensino Superior, que denotam pesquisas voltadas para a formação de graduandos em licenciaturas e futuros professores no sentido de aprimorar e desenvolver novas habilidades, discutindo novas propostas metodológicas para a educação/ensino de Química, dando ênfase ao uso de mídias tecnológicas em sala de aula. Na concepção de Lima e Medeiros (2016, p.82), "ao capacitar os professores em Tecnologias de Informação e Comunicação (TIC), a proposta é construir autonomia, competências e criticidade no saber e no fazer pedagógico".

A categoria geral apresenta um número expressivo de trabalhos direcionados aos diversos níveis de ensino, que podem ser considerados como pesquisas importantes aos profissionais da química para o desenvolvimento de novas propostas e métodos de ensino mediadas pelas tecnologias de informação e comunicação que podem contribuir para a educação/ensino de Química.

É importante ressaltar que, a partir da análise dos dados relacionados ao Ensino Fundamental, Técnico e EJA, se evidenciam uma carência de pesquisas direcionadas a estes níveis de ensino. Dessa forma, o baixo número de trabalhos pode indicar que a educação/ensino de Química nesses níveis ainda possa estar centrada no modelo de ensino tradicional e conteudista, sem uma articulação metodológica relacionada com as mídias tecnológicas em um contexto social e cultural na educação.

Conforme apontava Fumagalli (1998), no final dos anos de 1990, a Ciência escolar era composta por um corpo de conteúdo, procedimentos e atitudes com base em um conhecimento erudito. A enorme quantidade de conteúdos existentes no currículo escolar leva muitos docentes a pensarem em quantidade ao invés de qualidade, de modo a suprimir as contribuições que os educandos podem produzir aos elementos estudados. Em razão disto, o processo de ensino e aprendizagem pode se encontrar fragmentado e levar a perda de interesse, dificultando, assim, a apropriação de conhecimentos relevantes à vida cotidiana na sociedade. 
Nesse sentido, Castro e Costa (2011, p.26) relatam que:

É consenso entre os pesquisadores da área da educação, que o ensino tradicional pode apresentar muitas desvantagens, se destacando, a maneira como ocorre à transmissão do conhecimento, que é unidirecional, ou seja, o professor expõe o conteúdo de maneira que o aluno não possa exercer sua criticidade, sendo apenas um ouvinte.

De acordo com as ideias expostas, acredita-se que se faz necessário instigar os estudantes, a partir das séries iniciais da educação básica, quanto à utilização das tecnologias nos espaços escolares, para que o educando possa adquirir novas percepções sobre as diversas formas e recursos que podem contribuir para promoção da melhoria no processo educativo na educação/ensino de Química através do seu uso significativo e adequado.

As tecnologias proporcionam uma construção de saberes a partir de comunicabilidades interativas em um mundo de pluralidades, ou seja, sem limitações geográficas, culturais e a troca de conhecimentos e experiências é constante (OLIVEIRA; MOURA; SOUZA, 2015). É importante, ainda, salientar que estas propostas articuladas com as ideias apresentadas poderão corroborar para a construção de conhecimentos dos educandos de forma a promover uma maior compreensão de mundo em um panorama contextualizado e interdisciplinar.

\section{Considerações finais}

Com base na análise dos trabalhos publicados nos anais do ENEQ nos últimos dez anos na linha temática TIC, demonstrou-se que a produção da temática vem ganhando relevância a cada edição do evento, conforme revelam os dados. Ou seja, pesquisadores e educadores da área de educação/ensino de Química têm se dedicado a investigar a temática TIC como possibilidade educacional.

Foi observado que, em relação à distribuição regional das pesquisas, o maior número de publicações entre os estados foi nas regiões do (Sudeste, Nordeste e Centro-Oeste), sinalizando ainda para um cenário de pesquisas ainda carentes nos estados brasileiros das regiões (Norte e Sul). 
Vale destacar que, em relação aos níveis de ensino, ficou evidenciado que o Ensino Médio apresenta uma variedade de pesquisas no que tange às abordagens tecnológicas no ensino. Já nas propostas de pesquisas para o Ensino Fundamental, Técnico e EJA, percebeu-se que os números ainda são incipientes, carecendo ser mais explorada. No Ensino Superior, apesar dos dados apresentados demostrarem um número significativo de pesquisas, é notável que os cursos de formação inicial de professores ainda carecem de práticas pedagógicas que versem novas abordagens de ensino mediadas pelas TIC, a fim de favorecer a todos aos diversos níveis de ensino.

Por fim, pode se concluir que se evidência a necessidade de novas pesquisas com abordagens relacionadas ao estudo da temática TIC na educação/ensino de Química, com propostas para potencializar a prática docente, uma vez que este campo de pesquisa ainda apresenta-se muito produtivo para novos estudos e pesquisas que se apliquem aos diferentes níveis de ensino.

\section{Referências}

BARDIN, L. Análise de Conteúdo. Tradução de Luís Antero Reto; Augusto Pinheiro. São Paulo: Edições 70, 2011. 279 p. Disponível em: <https://www.ets.ufpb.br/pdf/2013/2\%20Metodos\%20quantitat\%20e\%20qualitat $\% 20-$

\%20IFES/Bauman,\%20Bourdieu,\%20Elias/Livros\%20de\%20Metodologia/Bardi n\%20-\%201977\%20-\%20An\%C3\%A1lise\%20de\%20Conte\%C3\%BAdo.pdf $>$ Acesso em: 17 de set. 2020;

CASTRO, B. J. D.; COSTA, P. C. F. Contribuições de um jogo didático para o processo de ensino e aprendizagem de Química no Ensino Fundamental segundo o contexto da Aprendizagem Significativa. Revista Electrónica de Investigación en Educación en Ciencias, Buenos Aires, v. 6, n. 2, 2011, p. 25-37;

CABRAL, W. A.; CASTRO, B. M. L. DE. A importância da escrita na formação inicial de professores de química: um olhar a partir da revisão de literatura e da vivência de uma bolsista do Pibid. Pesquisa e Debate em Educação, v. 8, n. 1, p. 670-687, 11.

FERNANDES, M. E.; SCHIMIGUEL, J.; PEREIRA, M. A.; AMBROGI, I. H.; OKANO, M. T. A educação num ritmo diferente de aprendizagem e interação o papel do docente como facilitador na educação à distância em um curso 
superior de tecnologia. Revista de Ensino de Ciências e Matemática, v. 10, n. 4, 2019, p. 01-19;

FLORES, A. M. Educação mediada pelas tecnologias da informação e comunicação. São Paulo: Senac, 2018. 300 p.;

FONSECA, R. C. V. D. Metodologia do Trabalho Cientifico. 1ª . ed. Curitiba: IESDE BRASIL, v. rev, 2012. 90 p.;

FUMAGALLI, L. O Ensino de Ciências Naturais no Nivel Fundamental da Educação Forma: Argumentos a seu Favor. In: WEISSMANN, H. Didática das Ciências Naturais: contribuições e reflexões. Porto Alegre: Artmed, 1998. Cap. 1, p. 13-29. Disponível em: <https://edisciplinas.usp.br/pluginfile.php/271575/mod resource/content/2/cap1 weissmann.pdf>. Acesso em:28 set. 2020;

JUNIOR, D. P. F.; CIRINO, M. M. A Utilização das TIC no Ensino de Química Durante a Formação Inicial. Revista Debates em Ensino de Química, Recife, v. 2, n. 2, 2016, p. 102-113;

LEITE, B. S. Tecnologias no Ensino de Química: Teoria e Prática na Formação. 1. ed. Curitiba: Appris, 2015;

LEITE, B. S.; LEÃO, M. B. C. Contribuição da Web 2.0 como ferramenta de aprendizagem: um estudo de caso. Revista Brasileira de Ensino de Ciência e Tecnologia, v. 8, n. 4, 2015, p. 288-315;

LIMA, A. L. S. D.; MEDEIROS, L. M. O Lúdico na Formação de Professores da Educação Básica na Capacitação em TIC. Informática na Educação: teoria \& prática, Porto Alegre, v. 19, n. 3, 2016, p. 81-93;

LUCENA, G. L.; SANTOS, V. D. D.; SILVA, A. G. D. Laboratório virtual como alternativa didática para auxiliar o ensino de química no ensino médio. Revista Brasileira de Informática na Educação, v. 21, n. 2, 2013, p. 27-36;

MACHADO, A. S. Uso de Softwares Educacionais, Objetos de Aprendizagem e Simulações no Ensino de Química. Revista Química Nova na Escola, São Paulo, v. 38, n. 2, 2016, p. 104-111;

MARTINS, S. O.; SERRÃO, C. R. G.; SILVA, M. D. D. B. O USO DE SIMULADORES VIRTUAIS NA EDUCAÇÃO BÁSICA: UMA ESTRATÉGIA PARA FACILITAR A APRENDIZAGEM NAS AULAS DE QUÍMICA. Revista Ciências \& Ideias, Rio de Janeiro, v. 11, n. 1, 2020, p. 216-233;

MATSUMOTO, F. M.; KUWABARA, I. H.; AIRES, J. A.; GUIMARÃES, O. M. A pesquisa na formação inicial de professores de química: relato de uma experiência na UFPR. In: Anais do XIV Encontro Nacional de Ensino de Química, 2008, Curitiba. Anais... Curitiba: UFPR, 2008.

NOGUEIRA, K. S. C.; GOES, L. F.; SKEIKA, T.; BACCON. A. L. P.; FERNANDES, C.; FREIRE, L. I. F. O ENEQ como espaço de socialização das 
ações do PIBID e de pesquisas sobre o programa. In: Anais do XVIII Encontro Nacional de Ensino de Química, 2016, Florianópolis. Anais... Florianópolis: UFSC, 2016.

OLIVEIRA, C. D.; MOURA, S. P.; SOUSA, E. R. D. TIC's na Educação: a Utilização das Tecnologias da Informação e Comunicação na Aprendizagem do Aluno. Pedagogia em Ação, Belo Horizonte, 7, 2015, p. 75-95;

OLIVEIRA, P. A. D.; NASCIMENTO, F. M. L. M.; BOTTENTUIT JUNIOR, J. B. Os Reflexos Docentes Sobre o Uso das Tecnologias. Anais do III Simpósio Nacional de Tecnologias Digitais na Educação. São Luís: EDUFMA. 2018. p. 177-190;

PAULETTI, F.; CATELLI, F. Tecnologias digitais: possibilidades renovadas de representação da química abstrata. Acta Scientiae, 2013, p. 383-396;

SALLA, H.; CAIXETA, J. E.; SILVA, R. L. J. D. Química no dia-a-dia: A mediação do conhecimento a partir de blog e outras tecnologias da informação e comunicação. Atas do $6^{\circ}$ Simpósio Internacional em Educação e Comunicação. Aracaju: Anais Eletrônicos. 2015. p. 89-94;

SILVA, V. D. A.; SOARES, M. H. F. B. O uso das tecnologias de informação e comunicação no ensino de Química e os aspectos semióticos envolvidos na interpretação de informações acessadas via web. Ciência e Educação, Bauru, v. 24,2018 , p. $639-657$;

SOARES, M. H. F. B.; MESQUITA, N. A. D. S.; REZENDE, D. B. O ensino de química e os 40 Anos da SBQ: o desafio do crescimento e os novos horizontes. Química Nova, São Paulo, v. 40, n. 6, 2017, p. 656-662;

SOUSA, R. P. D.; MOITA, F. M. G. D. S. C.; CARVALHO, A. B. G. Tecnologias Digitais na Educação. Campina Grande: EDUEPB, 2011. 276 p;

SOUZA, G. S. D.; SANTOS, A. R. D.; DIAS, V. B. Metodologia da pesquisa científica: a construção do conhecimento e do Pensamento Científico no Processo de Aprendizagem. Porto Alegre: Editora Animal, 2013;

TAVARES, R.; SOUZA, R. O. O.; CORREIA, A. D. O. UM ESTUDO SOBRE A "TIC" E O ENSINO DA QUÍMICA. Revista Gestão, Inovação e Tecnologias GEINTEC, São Cristovão, 2013, p. 155-167;

WENZEL, J. S.; MARTINS, J. L. de C.; BRATZ, G. E. A prática da escrita na formação inicial de professores de Química. Revista Docência do Ensino Superior, Belo Horizonte, v. 9, p. 1-16, 2019. DOI: 10.35699/22375864.2019.2482. Disponível em: <https://periodicos.ufmg.br/index.php/rdes/article/view/2482>. Acesso em: 20 fev. 2021. 


\section{Sobre os Autores}

Geovane de Melo Leal

geovanemelo_26@hotmail.com

Licenciado em Química pela Universidade Federal do Piauí (UFPI). Especialista em Metodologia do Ensino de Química pelo Centro Universitário Internacional (UNINTER). Pós-Graduando em Educação e Ensino de Ciências pelo Instituto Federal de Educação, Ciência e Tecnologia do Maranhão (IFMA).

\section{Davi da Silva}

dsdavi@ufpi.edu.br

Graduado em Licenciatura e Bacharelado em Química pela Universidade Regional de Blumenau (FURB), Mestre e Doutor em Química pela Universidade Federal de Santa Catarina.

\section{Dihêgo Henrique Lima Damacena}

dihegohenrique@yahoo.com.br

Graduado em Licenciatura Plena em Química pela Universidade Federal do Piauí (UFPI). Mestre em Química Analítica pelo Programa de Pós-Graduação em Química (PPGQ-UFPI). Doutorando em Química pela Universidade Federal do Piauí (UFPI), no Programa de Pós Graduação em Química (PPGQ), na área de Físico Química.

\section{Herbert Gonzaga Sousa}

herbertgonzaga19@gmail.com

Graduado em Licenciatura em Química pela Universidade Estadual do Piauí (UESPI). Possui Mestrado em Química na área de Bioprospecção fitoquímica pela Universidade Estadual do Piauí- UESPI. 